\title{
Fundus albipunctatus
}

INSERM

\section{Source}

INSERM. (1999). Orphanet: an online rare disease and orphan drug data base. Fundus albipunctatus. ORPHA:227796

Fundus albipunctatus is a rare, genetic retinal dystrophy disorder characterized by the presence of numerous small, round, yellowish-white retinal lesions that are distributed throughout the retina but spare the fovea. Patients present in childhood with nonprogressive night blindness with prolonged cone and rod adaptation times. The macula may or may not be involved, which may result in a decrease of central visual acuity with age. 